\title{
DEVELOPMENT OF RENAL DOSING GUIDELINES FOR NONSTEROIDAL ANTI-INFLAMMATORY DRUGS AND ANTIBIOTICS - A PROSPECTIVE STUDY
}

\author{
MAHESHWARI P*, NASREEN ASHRAF M, SHANMUGARAJAN TS, SHANMUGASUNDARAM P \\ Department of Pharmacy Practice, School of Pharmaceutical Sciences, Vels University, Pallavaram, Chennai, Tamil Nadu, India. \\ Email: mahe.mpharm@gmail.com
}

Received: 10 October 2018, Revised and Accepted: 11 December 2018

\section{ABSTRACT}

Objectives: The objectives of this study were to determine the impact of renal dosing guidelines on prescribing pattern for nonsteroidal antiinflammatory drugs and antibiotic in patients with chronic kidney disease (CKD).

Methods: This was a prospective interventional study. The study was divided into two phases, pre-intervention and post-intervention phases. Data regarding the kidney function and the pattern of drug dosing will record in the pre-intervention phase. Pocket guides were prepared for the drug dosing in renal impairment and were distributed to clinicians and the pharmacist as a part of intervention. In the post-intervention phase, the dosing pattern of renal eliminated drugs was observed for any improvement. The patterns of dosing of renal eliminated drugs were compared in both the phases.

Results: In pre-interventional phase, a total of 43 cases were reviewed, 20 of them were non-hemodialysis (non-HD) (9 female and 11 male) cases with a mean \pm standard deviation (SD) age of 56.05+8.22 (56) and 23 were undergoing HD (11 female and 12 male) cases with a mean \pm SD age of $56.72+6.85(56)$. In the post-intervention phase, a total of 41 cases were reviewed, 22 of them were non-HD (12 female and 10 male) cases with a mean \pm SD age of $55.85+6.87$ (57) and 19 were undergoing HD (10 female and 9 male) cases with a mean \pm SD age of 55.77+8.39 (56.6).

Conclusion: Health-care professionals have an important responsibility in monitoring the dose for renal impairment patients. Development of renal dosing guidelines for patients hospitalized with CKD can improve the pattern of prescribing in renal failure population.

Keywords: Renal dose, Guidelines, Nonsteroidal anti-inflammatory drugs, Antibiotics.

(C) 2018 The Authors. Published by Innovare Academic Sciences Pvt Ltd. This is an open access article under the CC BY license (http://creativecommons. org/licenses/by/4. 0/) DOI: http://dx.doi.org/10.22159/ajpcr.2018.v11s4.31735

\section{INTRODUCTION}

The kidneys are bean-shaped organs found on the left and right sides of the body in vertebrates [1,2]. The nephron is the structural and functional unit of the kidney. Each adult kidney contains around one million nephrons. The nephron utilizes four processes to alter the blood plasma which flows to it: Filtration, reabsorption, secretion, and excretion [3,4]. The kidneys also carry out functions independent of the nephron. For example, they convert a forerunner of Vitamin D to its active form, calcitriol, and synthesize the hormones such as erythropoietin and renin [5,6]. Renal physiology was the study of kidney function. Nephrology is the medical specialty which addresses diseases of kidney function, which include chronic kidney disease (CKD), nephritis and nephritic syndrome, acute kidney injury, and pyelonephritis. Urology addresses diseases of the kidney (and urinary tract) anatomy which include cancer, renal cysts, kidney stones and ureteral stones, and urinary tract obstruction $[7,8]$. Dialysis and kidney transplantation are used to treat kidney failure; one (or both sequentially) of these are almost always used when renal function drops below $15 \%$. Nephrectomy was frequently used to cure renal cell carcinoma $[9,10]$.

\section{METHODS}

This was a prospective interventional study. Subjects will be recruited according to selection criteria. A structured data collection form is designed to collect the information from the case sheets of the patients. The study was divided into two phases, pre-intervention and post-intervention phases. Data regarding the kidney function and the pattern of drug dosing will record in the pre-intervention phase. Pocket guides were prepared for the drug dosing in renal impairment and were distributed to clinicians and the pharmacist as a part of intervention. In the post-intervention phase, the dosing pattern of renal eliminated drugs was observed for any improvement. The patterns of dosing of renal eliminated drugs were compared in both the phases. Ethical committee approval no. VISTAS-SPS/IEC/IV/2017/07.

\section{RESULTS}

In the pre-interventional phase, a total of 43 cases were reviewed, 20 of them were non-hemodialysis (non-HD) ( 9 female and 11 male) cases with a mean \pm standard deviation (SD) age of $56.05+8.22$ (56) and 23 were undergoing HD ( 11 female and 12 male) cases with a mean \pm SD age of $56.72+6.85$ (56). In the post-intervention phase, a total of 41 cases were reviewed, 22 of them were non-HD (12 female and 10 male) cases with a mean \pm SD age of $55.85+6.87$ (57) and 19 were undergoing HD (10 female and 9 male) cases with a mean \pm SD age of $55.77+8.39$ (56.6) (Table 1). The number of drugs that prescribed was found to be 479 . The number of nonsteroidal anti-inflammatory drugs (NSAIDs) and Antibiotics prescribed was found to be 59 for non hemodyalitic patients and 57 for hemodyalitic patient. The number of NSAIDs that required dose adjustments was found to be 13 for non-HD patients and 11 for HD patients. The number of antibiotics that required dose adjustments was found to be 16 for non-HD patients and 17 for HD patients. (Table 2). As a part of intervention study, pocket guides were prepared for the NSAIDs and antibiotic drug dosing in renal impairment and were distributed to the clinician. Post-intervention, the number of drugs that prescribed was found to be 410 . In that, the total number of NSAIDs and antibiotics prescribed was found to be 65 for non-HD patients and 62 for HD patients. The number of NSAIDs that required dose adjustments was found to be 6 for non-HD patients and 9 for HD patients. The number of antibiotics that required dose adjustments was found to 
Table 1: Demographic profile of study population

\begin{tabular}{|c|c|c|c|c|}
\hline \multirow[t]{2}{*}{ Demographics } & \multicolumn{2}{|l|}{ Pre-intervention } & \multicolumn{2}{|c|}{ Post-intervention } \\
\hline & Non-HD (20) & HD (23) & Non-HD (22) & HD (19) \\
\hline \multicolumn{5}{|l|}{ Gender } \\
\hline Female (\%) & $9(45)$ & $11(47.82)$ & $12(54.54)$ & $10(52.63)$ \\
\hline Male (\%) & $11(55)$ & $12(52.17)$ & $10(45.45)$ & $9(47.36)$ \\
\hline \multicolumn{5}{|l|}{ Age } \\
\hline Mean+SD (median) & $56.05+8.22(56)$ & $56.72+6.85(56)$ & $55.85+6.87(57)$ & $55.77+8.39(56.6)$ \\
\hline $\begin{array}{l}\text { Serum creatinine } \\
\text { Mean+SD (median) Serum creatinine }\end{array}$ & $5.03+2.01(5.2)$ & $5.33+2.37(5.2)$ & $5.18+1.90(5.2)$ & $5.00+1.72(4.9)$ \\
\hline
\end{tabular}

Non-HD: Non-hemodialysis, SD: Standard deviation

Table 2: Number of medications prescribed in study population

\begin{tabular}{|c|c|c|c|c|}
\hline \multirow[t]{2}{*}{ Category } & \multicolumn{2}{|c|}{ Pre-intervention } & \multicolumn{2}{|c|}{ Post-intervention } \\
\hline & Non-HD & HD & Non-HD & HD \\
\hline Total number of prescriptions & 20 & 23 & 22 & 19 \\
\hline Total number of NSAIDs and antibiotics prescribed & 59 & 57 & 65 & 62 \\
\hline Number of antibiotics dosed appropriately & 18 & 15 & 28 & 23 \\
\hline Number of NSAIDs dosed appropriately & 12 & 11 & 23 & 24 \\
\hline Number of NSAIDs dosed in appropriately & $13(63.15 \%)$ & $14(63.63 \%)$ & $6(28.57 \%)$ & $9(50 \%)$ \\
\hline Number of antibiotic dose in appropriately & $16(84.21 \%)$ & $17(77.27 \%)$ & $8(49.76 \%)$ & $6(33.33 \%)$ \\
\hline
\end{tabular}

NSAIDs: Nonsteroidal anti-inflammatory drugs, Non-HD: Non-hemodialysis

Table 3: Details of the type of dosing adjustment needed

\begin{tabular}{lll}
\hline Type of adjustment & Pre-intervention & Post-intervention \\
\cline { 2 - 3 } & Number of drugs, $\mathbf{n = 6 0}(\mathbf{\%})$ & Number of drugs, $\mathbf{n = 2 9}(\mathbf{\%})$ \\
\hline Dose reduction & $28(46.6)$ & $11(37.9)$ \\
Change in dosing interval & $24(40)$ & $8(27.5)$ \\
not recommended & $8(13.3)$ & $10(34.4)$ \\
\hline
\end{tabular}

Table 4: Impact of pocket guide on dosing adjustments

\begin{tabular}{|c|c|c|c|c|c|}
\hline \multirow[t]{2}{*}{ Parameters } & \multicolumn{2}{|c|}{ Pre-intervention } & \multicolumn{2}{|c|}{ Post-intervention } & \multirow[t]{2}{*}{$p$ value } \\
\hline & Total & Inappropriate (\%) & Total & Inappropriate (\%) & \\
\hline $\begin{array}{l}\text { In non-HD } \\
\text { NSAIDs }\end{array}$ & 25 & $13(63.15)$ & 29 & $6(28.57)$ & $0.0163^{*}$ \\
\hline Antibiotics & 34 & $16(77.27)$ & 36 & $8(49.76)$ & $0.0287^{*}$ \\
\hline $\begin{array}{l}\text { In HD patients } \\
\text { NSAIDs }\end{array}$ & 25 & $14(63.63)$ & 33 & $9(50)$ & $0.0268^{*}$ \\
\hline Antibiotics & 32 & 17 (84.21) & 29 & $6(33.33)$ & 0.0090 \\
\hline
\end{tabular}

NSAIDs: Nonsteroidal anti-inflammatory drugs, Non-HD: Non-hemodialysis

be 8 for non-HD patients and 6 for HD patients. (Table 2). The type of dosage adjustments needed was found to be dose reduction in $46 \%$ (28 drugs) of the drugs for pre-intervention phase and $37.9 \%$ (11 drugs) in post-intervention, change of dosing interval in $40 \%$ (24 drugs) of the drugs in pre-intervention and $27.5 \%$ (8 drugs) in post-intervention, and about $13.3 \%$ ( 8 drugs) in pre-intervention and $34.4 \%$ (10 drugs) in post-intervention which were not recommended for the prescribing in renal function (Table 3). By comparing the results of post- and preintervention phases, it is clear that there is a significant impact of the dosing guidelines in the form of pocket guides in improving the dosing pattern of the renally eliminated drugs. The rate of inappropriateness in dosing was significantly reduced in post-intervention phase as compared to pre-intervention phase. Inappropriateness in dosing was significantly reduced in antibiotics from $77.27 \%$ to $49.76 \%$ ( $\mathrm{p}=0.0287^{*}$ ) in non-HD patients and NSAIDs reduced its inappropriateness of dosing from $63.15 \%$ to $28.57 \%$ in non-HD patients $\left(\mathrm{p}=0.0163^{*}\right)$. Furthermore, inappropriateness in dosing was significantly reduced in antibiotics from $84.21 \%$ to $33.33 \%$ in HD patients $\left(\mathrm{p}=0.0090^{* *}\right)$ and NSAIDs reduce its inappropriateness in dosing from $63.63 \%$ to $50 \%$ in HD patients (Table 4).

\section{DISCUSSION}

By comparing the results of post- and pre-intervention phases, it is clear that there is a significant impact of the dosing guidelines in the form of pocket guides in improving the dosing pattern of the renally eliminated drugs. The rate of inappropriateness in dosing was significantly reduced in post-intervention phase as compared to pre-intervention phase. Inappropriateness in dosing was significantly reduced in antibiotics from $77.27 \%$ to $49.76 \%$ ( $\mathrm{p}=0.0287^{*}$ ) in non-HD patients and NSAIDs reduced its inappropriateness of dosing from $63.15 \%$ to $28.57 \%$ in non-HD patients ( $\left.\mathrm{p}=0.0163^{*}\right)$. Furthermore, inappropriateness in dosing was significantly reduced in antibiotics from $84.21 \%$ to $33.33 \%$ in HD patients $\left(\mathrm{p}=0.0090^{* *}\right)$ and NSAIDs reduce its inappropriateness in dosing from $63.63 \%$ to $50 \%$ in HD patients 


\section{CONCLUSION}

The prevalence of CKD is increasing and polypharmacy is common. There is a need to monitor the dosing of drugs in those patients to avoid the adverse effects, to reduce the length of stay in the hospital, and to control the unnecessary cost of medications Antibiotic and NSAID prescriptions required dosage adjustment based on patient's renal function. Health-care professionals have an important responsibility in monitoring the dose for renal impairment patients. Development of renal dosing guidelines for patients hospitalized with CKD can improve the pattern of prescribing in renal failure population

\section{REFERENCES}

1. Coresh J, Selvin E, Stevens LA, Manzi J, Kusek JW, Eggers P, et al. Prevalence of chronic kidney disease in the united states. JAMA 2007;298:2038-47.

2. Savage R. A dangerous trio. Prescr Update 2003;23 Suppl 2:20.

3. Best Practice Advocacy Centre. Acute-on-chronic kidney disease: Prevention, diagnosis, management and referral in primary care. Best Pract J 2012;46:10-5.

4. Maheshwari P, Usha K, Ravichandiran V, Sarumathy S. The prospective study on quality of life with assessment of heamoglobin levels in chronic kidney disease patients. Res J Pharm Biol Chem Sci 2015;6 Suppl 5:480-7.

5. Eknoyan G, Marketos G, De Santo NG. History of nephrology. Spyros 1997;2:235.

6. Malhotra R, Kashani KB, Macedo E, Kim J, Bouchard J, Wynn S, et al. A risk prediction score for acute kidney injury in the intensive care unit. Nephrol Dial Transplant 2017;32:814-22.

7. Chertow GM, Burdick E, Honour M, Bonventre JV, Bates DW. Acute kidney injury, mortality, length of stay, and costs in hospitalized patients. J Am Soc Nephrol 2005;16:3365-70.

8. Chen S. Retooling the creatinine clearance equation to estimate kinetic GFR when the plasma creatinine is changing acutely. J Am Soc Nephrol 2013;24:877-88.

9. Mallat J, Meddour M, Durville E, Lemyze M, Pepy F, Temime J, et al. Decrease in pulse pressure and stroke volume variations after minifluid challenge accurately predicts fluid responsiveness $\dagger$. $\mathrm{Br} J$ Anaesth 2015;115:449-56.

10. Grams ME, Estrella MM, Coresh J, Brower RG, Liu KD, National Heart, Lung, and Blood Institute Acute Respiratory Distress Syndrome Network. et al. Fluid balance, diuretic use, and mortality in acute kidney injury. Clin J Am Soc Nephrol 2011;6:966-73. 